\title{
Stock Market Valuation Using The P/E Ratio: A Hands-On Exercise
}

\author{
Puneet Jaiprakash, Minnesota State University-Mankato, USA
}

\begin{abstract}
Finance professors and media frequently use the P/E ratio of the $S \& P 500$ Index to gauge whether the aggregate stock market is correctly valued at a given point in time. This article presents an assignment that introduces students to the concept of stock market valuation via a hands-on exercise. In particular, it requires students to use an EXCEL template to calculate various versions of the P/E ratio (trailing, forward, operating, and Shiller's), gauge whether the stock market is correctly valued, undervalued or overvalued, and then examine the sensitivity of these inferences to using different versions of this ratio. The entire exercise can be implemented using data available in the public domain.
\end{abstract}

Keywords: Stock Market Valuation; P/E Ratio; Shiller’s P/E; Behavioral Finance; S\&P 500

\section{INTRODUCTION}

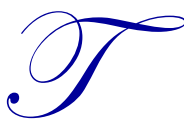

his article presents a hands-on exercise that allows students to answer the following question, "Is the aggregate stock market correctly valued?" To this end, they use data provided in an EXCEL template to compute the price-to-earnings ratio (P/E hereafter) of the stock market and then determine whether it is correctly valued, undervalued or overvalued. Next, they examine whether this conclusion is sensitive to different versions of the P/E - trailing, operating, forward and Shiller's (see Table 1 for a summary). Since this is indeed the case, students explore the reasons for these differences by comparing and contrasting different versions of the ratio. Finally, they read a recent article from The Wall Street Journal (WSJ hereafter) to understand how they would invest money based on the conclusions from the above steps.

Table 1: Different Versions of the P/E Ratio

\begin{tabular}{|l|l|}
\hline \multicolumn{1}{|c|}{ Ratio } & \multicolumn{1}{c|}{ Definition } \\
\hline Trailing P/E & Quarter-end value of S\&P 500 divided by sum of earnings over the past four quarters \\
\hline Operating P/E & $\begin{array}{l}\text { Quarter-end value of S\&P 500 divided by sum of operating earnings over the past four } \\
\text { quarters }\end{array}$ \\
\hline Forward P/E & $\begin{array}{l}\text { Quarter-end value of S\&P 500 divided by sum of projected earnings over the next four } \\
\text { quarters }\end{array}$ \\
\hline Shiller's P/E & $\begin{array}{l}\text { Inflation-adjusted quarter-end value of the S\&P 500 divided by average inflation-adjusted } \\
\text { earnings over the past 10 years. }\end{array}$ \\
\hline
\end{tabular}

The exercise has several objectives. The first one is to teach students to evaluate whether the stock market is correctly valued. Stock market valuation is an important concept that is relevant to investors. For example, investors frequently rebalance by selling stocks in their portfolio. If markets were efficient, market prices would either equal or quickly converge to fundamental values and the timing of the rebalancing would not matter. However, recent evidence (Barberis \& Thaler, 2003; Shleifer, 2000) suggests that market prices can deviate from fundamental values for long periods. Consequently, the timing of the rebalancing decision is important and a valuation metric, such as the $\mathrm{P} / \mathrm{E}$ for the stock market, can help guide this decision. It is not surprising that this metric is frequently discussed by not only the media but also professors. For example, WSJ frequently contains articles (Browning, 2010; Cheng, 2011; Constable, 2013; Gaffen, 2009; Hough, 2011; Lauricella, 2009, 2013; Levisohn, 2010a, 2010b, 2012; Zweig, 2011) discussing market valuation using the P/E and finance professors (Shiller, 2005; Siegel, 2008) use the ratio in their analysis of the stock market. Popular textbooks (Bodie, Kane, \& Marcus, 2009) explain the process of identifying a misvalued stock: (i) compute the fundamental value of a stock by 
using the dividend discount model or the method of comparables and (ii) if the stock's market price is lower (higher) than the fundamental value, the stock is undervalued (overvalued) and should be bought (sold). For the stock market, they discuss forecasting the end-of-year value, but do not discuss how to determine whether the stock market is correctly valued. The exercise thus addresses a gap in the existing texts and provides an introduction to behavioral finance.

The second objective is to demonstrate the applicability of textbook concepts to the real world. Students frequently feel that a class consists of abstract concepts that have little relevance to the real world. A hands-on exercise that illustrates a textbook concept and then asks students to apply these results to invest (virtual) money not only provides a deeper understanding of the concept but also demonstrates the relevance of textbook concepts. These outcomes meet current Association to Advance Collegiate Schools of Business (AACSB hereafter) standards ${ }^{1}$. For example, AACSB standards on Academic and Professional Engagement identify "learning activities that engage students" as one of the three activities that help schools connect theory and practice. Similarly, AACSB standards on Learning and Teaching list "application of knowledge" as one of the General Skill Areas for Bachelor's Degree Programs.

The third objective is to provide a valuable learning experience via faculty-student and/or student-student interaction. The exercise can be used as an in-class exercise or a group assignment. As an in-class exercise, the instructor could provide the template to students and then complete it in real time by leading a discussion that elicits answers from students. Thus, students are active rather than passive participants in the process of learning. Alternatively, it can be assigned as an exercise to be completed in groups. Students benefit by working in groups since they learn from each other and learn to work as team players. The obvious disadvantage is that some students might not do their fair share of work. This incentive to slack can be reduced by conducting anonymous peerevaluations after the submission date and/or having questions based on the assignment in the exam. Regardless of the manner in which it is administered, the exercise meets outcomes that are consistent with several AACSB standards. For example, Standard 10 recommends curricula that encourage student-faculty and student-student interactions. Similarly, Standard 9 lists "interpersonal relations and teamwork" as one of the General Skill Areas for Bachelor's Degree Programs.

\section{DESIGINING THE ASSIGNMENT}

The first step in this process is to choose an index for representing the stock market. The S\&P 500 is selected because it is frequently cited by the media. The next step is to collect all necessary variables from various public data sources to construct an EXCEL template that will be provided to students. A description of this process and the template is available from the author upon request. In brief, the template (see Figure 1 for a snapshot) contains quarterly data for the price, earnings and operating earnings for the S\&P 500, and the Consumer Price Index. It is worth mentioning that Robert Shiller's website provides monthly data on price and earnings of the S\&P 500 along with Shiller's $\mathrm{P} / \mathrm{E}^{2}$. Using a different data frequency (quarterly instead of monthly) prevents students from obtaining answers from his website.

\footnotetext{
1 The 2013 Business Accreditation Standards are located at http://www.aacsb.edu/accreditation/business/standards/2013/2013-businessstandards.pdf

${ }^{2}$ http://www.econ.yale.edu/ shiller/data.htm
} 


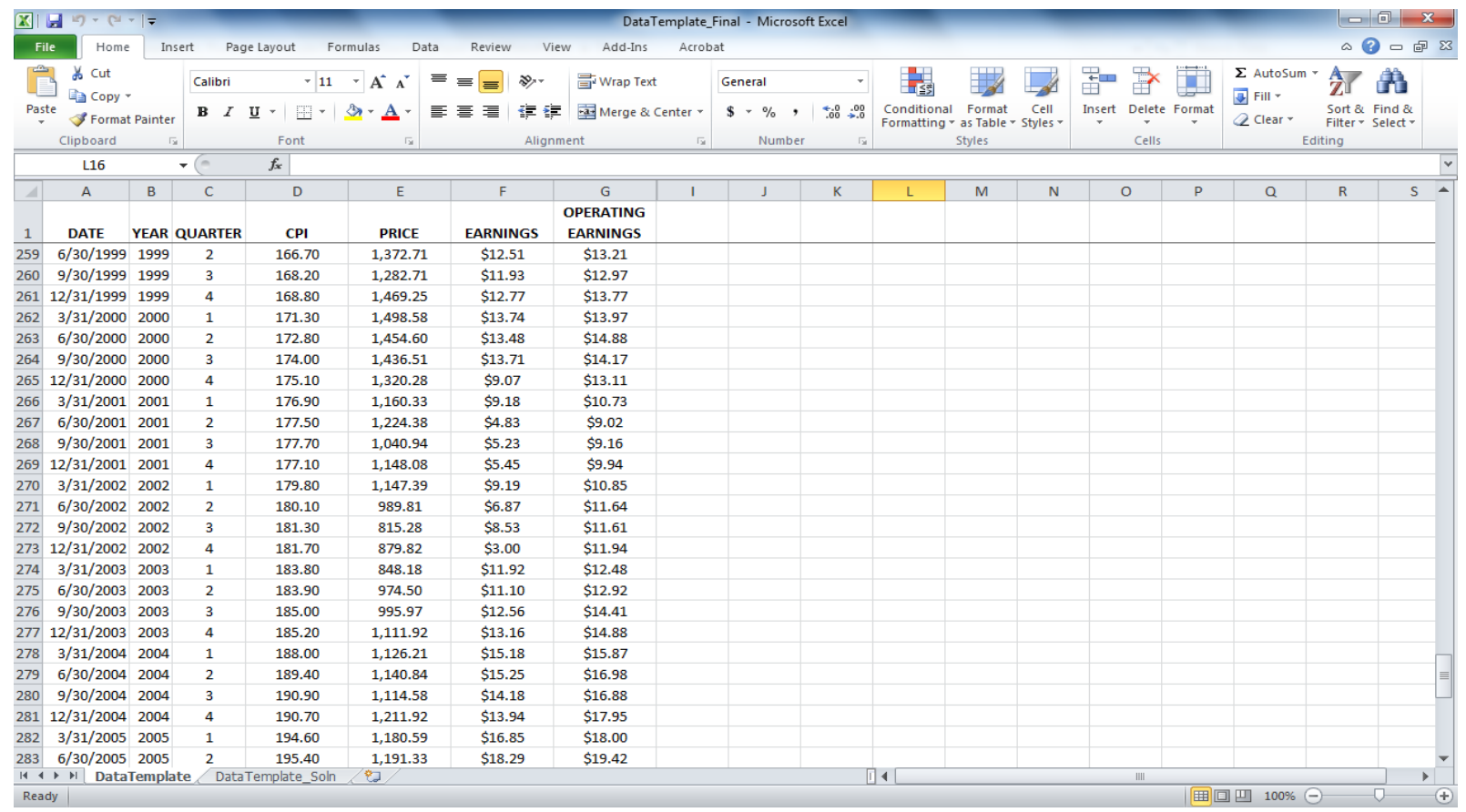

Figure 1: Snapshot of the Data Template

\section{THE ASSIGNMENT}

\section{Learning Objectives}

After completing this exercise, you will be able to do the following:

- Define and calculate different versions (trailing, operating, forward, and Shiller's) of the P/E for the stock market.

- $\quad$ Compare and contrast different versions of the P/E for the stock market.

- Identify the fundamental drivers of a stock's P/E and discuss why the ratio differs across stocks.

- $\quad$ Convert nominal variables to inflation-adjusted variables.

- $\quad$ Discuss stock market valuation, undervaluation, and overvaluation.

- $\quad$ Evaluate whether the stock market is correctly valued, undervalued, or overvalued.

- $\quad$ Determine how to invest your money if the stock market is undervalued or overvalued.

\section{Questions}

Follow the steps and answer the questions below:

1. Download the file "DataTemplatexlsx" from D2L. Rename the file to $<$ LastNameoftheFirstMemberofYourGroup >.xlsx. For example, if John Doe was the first member of your group, your file would be named Doe.xlsx. Table 2 summarizes data contained in the file. Unless specified otherwise, all variables are expressed in nominal terms.

Table 2: Data in EXCEL Template

\begin{tabular}{|l|c|c|}
\hline \multicolumn{1}{|c|}{ Name } & Date Range & Description \\
\hline CPI & 1935:Q1-2012:Q3 & Value of the Consumer Price Index \\
\hline Price & $1935: \mathrm{Q} 1-2012: \mathrm{Q} 3$ & Value of the S\&P 500 \\
\hline Earnings & $1935: \mathrm{Q} 1-2012: \mathrm{Q} 3$ & Reported Earnings per share for the S\&P 500 \\
\hline Operating Earnings & $1988: \mathrm{Q} 1-2012: \mathrm{Q} 3$ & Operating Earnings per share for the S\&P 500 \\
\hline
\end{tabular}


2. Using data in the columns labeled Price and Earnings, compute the (i) P/E for each quarter and (ii) the average $\mathrm{P} / \mathrm{E}$. To do so, first add a new column titled "P/E" and then compute the average of the values appearing in this column.

3. Using data in the columns labeled Price and Operating Earnings, compute the (i) operating P/E for each quarter and (ii) the average operating $\mathrm{P} / \mathrm{E}$. To do so, first add a new column titled "Operating P/E" and then compute the average of the values appearing in this column.

4. Using data in the columns labeled Price and Earnings, compute the (i) forward P/E for each quarter and (ii) the average forward $\mathrm{P} / \mathrm{E}$. To do so, first add a new column titled "Forward $\mathrm{P} / \mathrm{E}$ " and then compute the average of the values appearing in this column. Use the data in Table 3 as required.

Table 3: Additional Data for Earnings and Operating Earnings

\begin{tabular}{|l|c|c|}
\hline \multicolumn{1}{|c|}{ Date } & Earnings & Operating Earnings \\
\hline $12 / 31 / 2012$ & $\$ 21.24$ & $\$ 25.33$ \\
\hline $3 / 31 / 2013$ & $\$ 24.37$ & $\$ 26.33$ \\
\hline $6 / 30 / 2013$ & $\$ 25.40$ & $\$ 27.99$ \\
\hline $9 / 30 / 2013$ & $\$ 26.04$ & $\$ 28.70$ \\
\hline $12 / 31 / 2013$ & $\$ 24.90$ & $\$ 29.80$ \\
\hline
\end{tabular}

5. Using data in the columns labeled Price and Earnings, compute the (i) Shiller's P/E for each quarter and (ii) the average Shiller's P/E. To do so, first add a new column titled "Shiller's P/E" and then compute the average of the values appearing in this column.

6. Based on your answers to the above questions, first complete Table 4 and then answer questions (a) - (d) below. Please explain your reasoning for each question.

Table 4: Summary Statistics for Different Versions of the P/E

\begin{tabular}{|l|l|l|l|c|}
\hline \multicolumn{1}{|c|}{ Ratio } & \multirow{2}{*}{$\begin{array}{c}\text { Value } \\
\text { (On 09/28/2012) }\end{array}$} & Average & \multicolumn{2}{c|}{$\begin{array}{c}\text { Period Over Which Average Was } \\
\text { Computed }\end{array}$} \\
\cline { 3 - 5 } & & & $\begin{array}{c}\text { Start Date } \\
\text { (yyyy:q) }\end{array}$ & $\begin{array}{c}\text { End Date } \\
\text { (yyyy:q) }\end{array}$ \\
\hline Trailing P/E & & & \\
\hline Operating P/E & & & \\
\hline Forward P/E & & & \\
\hline Shiller's P/E & & & \\
\hline
\end{tabular}

a. Based on the trailing $\mathrm{P} / \mathrm{E}$, is the market correctly valued, undervalued or overvalued?

b. Based on the Operating $\mathrm{P} / \mathrm{E}$, is the market correctly valued, undervalued or overvalued? How does the Operating $\mathrm{P} / \mathrm{E}$ differ from the trailing $\mathrm{P} / \mathrm{E}$ ?

c. Based on the Forward P/E, is the market correctly valued, undervalued or overvalued? How does the Forward $\mathrm{P} / \mathrm{E}$ differ from the trailing $\mathrm{P} / \mathrm{E}$ ?

d. Based on Shiller's $\mathrm{P} / \mathrm{E}$, is the market correctly valued, undervalued or overvalued? Plot the trailing $\mathrm{P} / \mathrm{E}$ and Shiller's $\mathrm{P} / \mathrm{E}$ against time. What differences do you notice between these plots? Explain why these differences occur.

The next two questions are based on the WSJ article Peeling Back the Market's P/E (September 17, 2011).

7. Assume you have $\$ 5,000$ to invest and believe the forward P/E to be better than all other variations of the $\mathrm{P} / \mathrm{E}$ calculated above. Based on your answer in 6(c) and the article, how would you go about investing this money in the real world?

8. Based on the article, why does the P/E differ across stocks? In other words, why do some stocks have low $\mathrm{P} / \mathrm{E}$ but other stocks have high $\mathrm{P} / \mathrm{E}$ ?

\footnotetext{
${ }^{3}$ The article is located at http://online.wsj.com/article/SB10001424053111904491704576573241520154756.html
} 


\section{Final Step}

Please turn in the following items:

- $\quad$ Excel sheet submitted through the Dropbox tool on D2L

- Hard copy of your answers to the questions

\section{EXTENSIONS}

Instructors can extend this assignment in several ways to make it more interesting. For example, they can ask students to compute the average using data for a shorter time period, say 5-6 years - the typical length of a business cycle - rather than the entire time series. This would allow students to examine the sensitivity of their inferences to the time period used for computing averages. Alternately, they could compute the average over each segment of the business cycle (contraction and expansion). To this end, each quarter can be classified into Contraction or Expansion using data available at the National Bureau of Economic Research's (NBER) website ${ }^{4}$. The economic justification is the fact that the P/E varies with the business cycle; it is high (low) at the bottom (top) of a business cycle due to low (high) earnings. Based on the NBER data, a trough in economic activity occurred in June 2009 suggesting that we are currently in an expansion phase. Thus, the P/E (trailing, operating, forward, and Shiller's) should be compared to an average computed over all past expansion phases.

\section{CONCLUSION}

Since market prices can deviate from fundamentals for long periods of time, investors have to consider the market's current valuation before implementing their portfolio rebalancing decisions. This article has developed an assignment that introduces students to the concept of stock market valuation. To this end, it uses a hands-on exercise to acquaint students with a popular valuation metric - the P/E. The assignment demonstrates the real world relevance of textbook concepts to students; in addition, it enhances their ability to use spreadsheets and to produce and interpret graphs. From an educator's perspective, the assignment is easy to implement since it uses freely-available data and achieves several outcomes specified by the AACSB.

\section{TEACHING NOTE}

A teaching note discussing the answers to questions in the assignment is available from the author.

\section{ACKNOWLEDGEMENTS}

The author would like to thank his colleagues Hyuna Park, Steve Wilcox, and especially Harry Thiewes for helpful comments.

\section{AUTHOR INFORMATION}

Puneet Jaiprakash is an Assistant Professor in the College of Business at Minnesota State University, Mankato, USA. He received his Ph.D. from Virginia Polytechnic Institute and State University (Virginia Tech). His research interests are primarily in the area of asset pricing, mutual funds, and behavioral finance.

\section{REFERENCES}

1. Barberis, N. C., \& Thaler, R. H. (2003). A survey of behavioral finance. In Handbook of the economics of finance, Volume $1 B$ (pp. 1053-1124).

2. Bodie, Z., Kane, A., \& Marcus, A. (2009). Essentials of investments (8th ed.). McGraw-Hill/Irwin.

3. Browning, E. S. (2010, March 9). Worries rebound on bull's birthday. Wall Street Journal, p. A.1.

4. Cheng, J. (2011, August 15). The other shoe--earnings. Wall Street Journal, p. C.1.

\footnotetext{
${ }^{4}$ An Excel file with these dates is available at http://www.nber.org/cycles/cyclesmain.html\#announcements
} 
5. $\quad$ Constable, S. (2013, February 4). Price/earnings ratio. Wall Street Journal, p. R.9.

6. Gaffen, D. (2009, March 3). To P/E or not to P/E that isn't the appropriate question. Wall Street Journal, p. C.5.

7. Hough, J. (2011, September 17). Peeling back the market's P/E. Wall Street Journal, p. B.7.

8. Lauricella, T. (2009, May 11). By most measures, stocks no longer look cheap. Wall Street Journal, p. C.1.

9. Lauricella, T. (2013, February 11). Is the bull sprint becoming a marathon? Wall Street Journal, p. C1.

10. Levisohn, B. (2010a, August 30). The decline of the P/E ratio. Wall Street Journal, p. C.1.

11. Levisohn, B. (2010b, September 4). Is it time to scrap the fusty old P/E ratio? Wall Street Journal, p. B.9.

12. Levisohn, B. (2012, April 7). Why stocks look too pricey. Wall Street Journal, p. B.6.

13. Shiller, R. J. (2005). Irrational exuberance (2nd ed.). Princeton University Press.

14. Shleifer, A. (2000). Inefficient markets. Oxford University Press.

15. Siegel, J. (2008). Stocks for the long run (4th ed.). McGraw Hill.

16. Zweig, J. (2011, August 6). Stocks are cheaper, but they aren't cheap. Wall Street Journal, p. B.1. 